\title{
Risk terrain modeling for monitoring illicit drugs markets across Bogota, Colombia
}

\author{
José A. Escudero* and Boris Ramírez
}

\begin{abstract}
Colombia has gone from being a producer and exporter of illicit drugs to becoming a country where consumption also plays an important role. In Bogota, as result of specific policies adopted by the authorities that hit illicit drugs hot spots, the sale has gradually become more dispersed. Exacerbated by the emergence of new neighborhoods due to unplanned population growth, monitoring such markets becomes difficult for local authorities, which appeal to global statistics and surveys to design public policies. This work proposes a new methodology for monitoring the markets of three illicit psychoactive substances (cocaine, marijuana and basuco) while also providing insights into the spatial behavior of such markets. To estimate traded quantities and market values for each substance in Bogota, specific information is collected through surveying exercises with the police force making use of social mapping. Afterward, GIS techniques are applied to analyze such information along with crime data related to drug markets. Risk terrain modeling is applied to estimate the risk of existence of retail sale points and to clean the data for latter estimation of traded quantities and spatial distribution of drug markets.
\end{abstract}

Keywords: RTM, GIS, Drug market

\section{Background}

Over the past few decades, consumption of illicit drugs in Colombia has increased significantly, particularly in large cities where complex criminal structures take advantage of high population densities and crime rates to run illicit businesses (Alvarado 2013). However, it is also known to work the other way around in the sense that criminal organizations running illicit drugs markets develop capacities to regulate the markets through violence and, therefore, when such markets are established in urban areas, increases in homicides, personal injuries, robberies and violations of human rights are observed (Rengert et al. 2000; Robinson and Rengert 2006; Alvarado 2013).

Previous studies have demonstrated that drug dealing locations tend to cluster, especially in large cities (Rengert et al. 2000; Kennedy et al. 2011). Nevertheless, in Bogota, these concentrations of illicit drugs sale points are increasingly combined with a constellation of scattered sale points located in peripheral areas of the city.

\footnotetext{
*Correspondence: jescudero@ideaspaz.org

Knowledge Management Area, Fundación Ideas para la Paz, 100th St. 8A-37, Bogotá, Colombia
}

Most of them are a result of the emergence of new neighborhoods due to unplanned population growth and internal displacement. Another cause for scattered sale points are specific intervention policies adopted by the authorities that hit drug hot spots, making the sale more dispersed and sometimes invisible. Although these interventions are planned to counter the market, no baseline information for measuring their impact is available to date (Garzón et al. 2017).

All aforementioned characteristics of the city make market control initiatives difficult. Governments require innovative and practical solutions to measure and monitor these markets. In Colombia, past studies (Alvarado 2013) have identified the lack of information for reaching conclusions and recommendations. Historically, government entities have appealed mostly to global statistics and incomplete surveys to design control strategies (Departamento 2016). However, policy-makers need to understand the structure and even dynamics of illegal markets in order to produce preventive and corrective policies. In this way, drug market control could be more effective (Caulkins and Reuter 2010). This work addresses this need for information about the illegal drug markets 
in Bogota by proposing a novel methodology for monitoring such markets at a sub-neighborhood level, making use of risk terrain modeling (RTM), and available police records.

\section{Risk terrain modeling}

As proposed by Caplan et al. (2011), RTM aims to model spatial patterns of interaction between different variables and a crime outcome. Such models point to locations where specific environmental conditions increase the risk of crime or victimization. Extensive work has been carried out in the past by applying RTM to a wide array of case studies. Daley et al. (2016) applied RTM to evaluate the environmental factors thought to be more related to child maltreatment. Kennedy et al. (2015) studied the events and environmental features that have spatial influence and thus generate vulnerability to violence and assaults. This technique, widely applied in large cities of the United States (Barnum et al. 2016; Caplan et al. 2014, 2015), has also been explored for crime prediction in Europe (Dugato 2013; Kocher and Leitner 2015) and even Latin America (Oliveira et al. 2015). As explained by Caplan et al. (2014), RTM provides valuable information for police forces and the planning of intervention strategies. However, some authors have found cases where the predictive power of RTM is limited. Kocher and Leitner (2015) emphasize the importance of availability and quality of the risk data, and the fact that using risk variables reported in the literature may not apply to local conditions where the risk terrain model is to be used. Also, it is important to note the drawbacks of omitting the time dimension, since the distribution of events could change on a seasonal basis. Even though some these factors may affect the accuracy of RTM, it still outperforms other methodologies when mapping crime risk in complex environments (Drawve et al. 2016; Daley et al. 2016). This could be especially important for the case of Bogota where significant efforts in intelligence have been made during the past years (Garzón et al. 2017).

In terms of models for crime prediction applied in Colombia, the work by Barreras et al. (2016) uses crime data from 2011 and 2012 in Bogota to carry out a comparative analysis evaluating the outcome of different models for crime prediction on this data. To our knowledge, this is the first case study for modeling drug markets in Colombia.

Given the complexity and the illegality of the business, collecting reliable data on illegal drugs markets becomes an arduous task. Drug seizures and arrests are often used as proxies for illicit drugs supply. However, Jacobson and Webb (1999) and Oliveira et al. (2015) stress the limitations of using this data: first, seizures and arrests can be closer to governments' response to drug dealing and not to drugs supply itself and, secondly, these records may be biased by police corruption. Thus, as explained earlier, in order to design an effective monitoring system, the information provided by the National Police should be analyzed along with other information e.g. environmental conditions, related crimes and drug prices.

The work by Barnum et al. (2016) assesses urban environmental features that increase the risk of drug dealing at specific locations. They highlight, after examining 28 such variables, that foreclosures, problem landlords and broken street lights represent "ecological advantages" for the development of open-air illegal drug markets. However, these ecological advantages may vary between established locations for drug markets (retail sale points) and open-air drug dealing. Other variables were analyzed by Oliveira et al. (2015) using data from drug arrests from 2007 to 2011 and including socio-demographics from the 2010 Census. In this case, factors such as housing quality, socio-economic status, age at risk and residential tenure were highlighted as significant. In Bernasco and Block (2011), four categories of variables were studied: (1) infrastructural aspects at a census block level, (2) urban environmental variables, (3) registers of incidents related to drug-markets and (4) presence of offender anchor points. They found that ecological advantages were not only defined by environmental variables but also by known presence of illegal activities and crime in the zone. This raises the possibility of investigating both environmental features and crime records when evaluating the risk of existence of drug dealing locations. Moreover, drug prices should be closely tied to these variables since drug dealers seek strategic locations and conditions where profit margins are maximized. Hence, price distributions should also be included in the analysis given its direct influence on the market.

\section{Drugs market estimation}

By discovering the variables spatially correlated to drug sale points, it is possible to obtain an approximate distribution of illicit drugs markets across the city. This would provide valuable information to authorities and policymakers for purposes of calculating and monitoring markets at a smaller scale, enabling them to design more accurate intervention policies and strategies. To estimate such markets of illicit drugs, the United Nations Office on Drugs and Crime (UNODC) proposes a methodology that uses secondary information to calculate the global size of the drug market (UNODC 2005), using the following equations:

$$
\begin{aligned}
\text { quantity } & =\text { consumption }+ \text { seizures } \\
\text { value } & =\text { quantity } * \text { price }
\end{aligned}
$$


where quantity refers to traded quantity and value refers to the market value. As shown in (1), by using seizures, the model could determine the traded quantity of drugs under the assumption that seizures represent between 7 and 10\% (UNODC 2005). In addition, UNODC discusses the experience they have had in estimating the global drug market and proposes two types of method for such estimation: direct and indirect. Direct methods include household surveys and school surveys. This method approaches the drugs demand, estimating the number of consumers and multiplying by the amount consumed by each consumer. It may, however, underestimate the demand depending on how the surveys are carried out. For example, the 2016 Consumer Survey carried out in Bogota included people between 12 and 65 years old. This means that consumers under 12 or over 65 , as well as homeless people, who are great consumers, especially of marijuana and basuco, are not taken into account (Alcaldía de Bogotá 2016). In addition, it is possible that the respondent does not give complete information about their real consumption.

As indirect methods, UNODC considers three options: the multiplier method, the capture-recapture model and multivariate indicators. The multiplier method consists in establishing certain multipliers related to drug use and applying them to the consumer population. For example, if one of every five consumers were caught by the police, the total number of consumers can be obtained by multiplying the number of captures by 5 . The capture-recapture model is applied by observing the data of detentions for possession and comparing these records in two periods of time. This method has been widely used in the past (Robinson and Rengert 2006; McCord and Ratcliffe 2007). For example, assume that in the first period of time 5000 people were detained for illicit drugs possession and, during the second period of time, there were 2000 people. Assume further that comparing both records, 400 people appear to be in both periods, that is $20 \%$ of the 2000 people arrested. This would indicate that onefifth of the population is a consumer of that substance, so it is possible to estimate the total consumption in any specific region. The main limitation of this methodology lies in Colombian legislation. In the Supreme Court of Justice sentence SP2940 of 2016, the possession of narcotic, psychotropic or synthetic drugs is decriminalized in the amount prescribed by a doctor, or in cases where it can be proven that the person needs a certain dose as a consequence of his condition of consumer, addict or sick person. Thus, there are very few detentions of consumers and a capture-recapture methodology could not be applied to measure consumption. Finally, the multivariate indicators method uses all the information available at the local level, to then extrapolate it to a national or even global level. This method takes into account specific characteristics of the territory where the study is performed.

The methodology applied in this research is similar to the multivariate indicators described in the 2005 World Drug Report, which is based on seizures and drug prices to estimate market size. The method proposed in this work, is designed to estimate the market from the drug supply, and not from the demand. We propose monitoring illicit drugs markets through a combination of field work exercises with the police force and GIS techniques. We introduce RTM to model the distribution of illicit drugs and to improve our estimation of the market value at smaller scales. Three substances are analyzed: cocaine, marijuana and basuco (crack), since they are believed to have similar characteristics of sale (Alcaldía de Bogotá 2016). This methodology aims to model a more stable process of these markets which is carried out in retail sale points. It is also designed in a practical and replicable manner to perform such activities on a regular basis and to include the time dimension in future studies.

\section{Methods}

The Colombian police force has studied illicit drugs markets and identified two threats when it comes to distribution: (1) microtraffic, usually operating from retail sale points, which includes supply of drugs to illegal organizations in charge of (2) narcoretail or open-air distribution, which is the direct sale to consumers (Alvarado 2013). As mentioned before, this study aims to model the market by using information from the supply side, specifically we use information of retail sale points in Bogota, consisting in geographically fixed locations where supply of different substances is found. Secondary sources of information for this study involve crime records for 2016 and spatial information of urban features in the city, all of which will be further described.

\section{Gathering data about retail sale points location and characteristics}

To identify the presence of retail sale points in 2010, the Fundación Ideas para la Paz (FIP) and the Police Department carried out a series of social cartography exercises involving every single patrol squad in the city. The exercises consisted in locating the known retail sale points of illicit drugs in each police jurisdiction using the map of Bogota. Taking this past experience into account, this exercise was replicated in December of 2015 to gather even more information by working with the major officers of command of immediate action (CAIs). This time, 108 out of 111 CAI majors took part in the exercise; they were asked to draw the locations of retail sale points in their jurisdictions using a map of Bogota. For this second 
iteration, not only information about the sale was gathered, but also information about types of substances offered and corresponding price, if known. In this way, approximately $97 \%$ of the city territory was sampled. In order to assess reliability of the data, a nearest neighbors analysis was performed for both datasets from 2010 and 2015 , obtaining an observed mean distance of $363.3 \mathrm{~m}$ and $344.0 \mathrm{~m}$, respectively, failing to reject the hypothesis of clustered behavior. Such analysis showed that $85 \%$ of the data points from 2015 did not move more than $200 \mathrm{~m}$ from previous high density areas, even after 5 years. By comparing both datasets, it was also found that such areas are spatially consistent with common knowledge traffic zones in Bogota.

\section{Prices distribution for each substance}

To estimate the price distribution in the city's territory, the information gathered about prices of each substance at every police jurisdiction was used. In order to convert a discrete variable into a continuous one, an interpolation method was applied using ArcGIS ${ }^{1}$ to approximate the distribution of prices for each substance. At the end, we were able to obtain the prices for all three substances in locations where no information was collected before given the data points gathered around it.

\section{Estimation of traded quantity for each substance}

As mentioned earlier, a key variable for calculating the traded quantities of illicit drugs in Bogota are seizures. However, two specific flaws were identified in this data: (1) it involves every single operation of drug confiscation in the city, including outliers given by seizures at airports and hot spots interventions, and (2) the information also included small quantities which are seized by the police in operations against consumers. With the purpose of minimizing such drawbacks, the authors introduce two pre-processing steps for correcting this data, which are described below.

\section{Calculation of typical surveillance seizures}

For the purpose of dealing with the first problem, we introduce the concept of typical surveillance seizures (TSS). This is the quantity of drugs seized by a police patrol in a normal surveillance shift. For this, only seizures by the operational police command (DISEC) were taken into account, excluding seizures by special units such as the airport antinarcotics unit and intelligence units. In addition to this, outliers of drugs seized were

\footnotetext{
${ }^{1}$ The interpolation method applied in this step consists in inverse distance weighting (IDW) interpolation. This method predicts pixel values for a raster layer from a limited amount of sampled data points.
}

excluded from the analysis. ${ }^{2}$ From this filtered information, it was possible to obtain spatial behaviors of drug seizures using a Kernel Density calculation. ${ }^{3}$

Spatial estimation of the risk of existence of a retail sale point Since the interest of the present work focuses on illicit drugs market estimation from the supply point of view, seizure data was also corrected based on a model for risk of existence of retail sale points. This was performed in order deal with problem (2), filtering out seizures to consumers and leaving seizures associated with zones of high risk of sale points presence.

Based on the information collected about location of retail sale points, and using crime and environmental data, risk terrain modeling was applied so as to calculate the risk of existence of a retail sale point. For this, the RTMDx tool from Rutgers University was used (Caplan et al. 2015). This tool applies RTM modeling techniques for spatial data, and the results can be later visualized using any GIS software. RTMDx uses R as the calculation engine to estimate the risk using a generalized additive model for location, scale and shape (GAMLSS). This model estimates the risk of occurrence of an event (existence of a retail sale point for this case) as a function of proximity or density to different risk factors, ${ }^{4}$ as stated by Caplan et al. (2013). The tool selects the best model among a set of candidates based on the BIC (Bayesian Information Criterion) score. As a result, RTMDx proposes a model optimized for accuracy of prediction and also quantity of risk factors of the model, avoiding overfitting. In our work, the set-up was the same for all risk factors: both types of influence (operationalization) were evaluated; the spatial influence was taken as the third quartile of distances to the closest point; and the size of the grid was 100 by 100 , which is the approximate distance of a block in Bogota.

We use a cross-substances RTM model under the assumption that risk factors associated with illicit drugs expenses are common among traded substances in Bogota. Three families of variables were used as risk factors for this estimation: seizure data, crime records and environmental features. (1) Seizure data used was TSS for marijuana, cocaine and basuco, separately; (2) the crime variables included were homicides, personal injuries, motorcycle theft, vehicles theft, business theft and

\footnotetext{
${ }^{2}$ Outliers were defined as data points above the mean of each substance for more than three standard deviations.

3 Search radius for the Kernel estimation was equal to the mean of the nearest neighbors for every retail sale point. This for each substance.

4 This is presented as the operationalization of spatial influence. Proximity (i.e., Euclidean distance) means that being within a certain distance from risky features increases the likelihood of illegal behavior. Density assumes that high concentrations of risky features creates a unique context for illegal behavior and increases the likelihood of crime events at high density places.
} 
robbery, all reported by the System of Statistical, Criminal, Contravention and Operative Information of the National Police Department (SIEDCO); and (3) the environmental features proven to coexist with drug markets such as bars, schools, parking lots, parks, restaurants and universities from 2014. A total of 15 variables were used in the model. As response variable, location of known retail sale points was examined. For evaluating the quality of the data for families (1) and (2), certain aspects were considered. In the case of geocoding rate, it is worth noting that the National Police along with researchers from FIP, implemented in 2014 a new system for data collection based on geolocation of crime records, which minimizes geocoding rates problems at the cost of less than $10 \%$ error of geolocation accuracy (Ramirez et al. 2014). Approximate reporting levels in Bogota were examined for certain groups of variables when available: $79 \%$ for vehicles and motorcycles theft, 32\% for personal injuries and 25\% for robbery, as reported by the National Department of Statistics (DANE).

Given these groups of variables, the model should be described by the following expression:

$$
R\left(E_{t z}\right)=f(I, D, V)
$$

where $R\left(E_{t z}\right)$ is the risk of existence of a retail sale point as a function of seizures $I$, crime variables $D$ and environmental variables $V$. The data used to fit this model was gathered between January and November of 2016 .

\section{Model validation}

In order to evaluate model accuracy when predicting a risky zone, the data collected was randomly divided into two sets: a training set (70\% of the data points) used to build the model, and a test set (30\% of the data points) to assess the accuracy of the model when dealing with unknown data. The validation metric proposed in this work is similar to the one presented by Daley et al. (2016) and the predictive accuracy index (PAI) (Chainey et al. 2008), which could be further calculated using our validation method. After the model is obtained using RTMDx, a raster layer of the model described by (2) is obtained using ArcGIS, this is the risk of existence of retail sale points. This raster layer is divided in quintiles and reclassified to obtain polygons with five categories of risk on which known retail points are overlaid. In this way, we are able to calculate the percentage of points on all five zones of risk and establish a custom metric to evaluate the accuracy on the training and test sets.

\section{Estimation of traded quantity from TSS data}

Based on the RTM, the raster layer representing the risk of existence of retail sale points was rescaled from 0 to 1 . This raster layer was used as correction factor for the seizure distribution and, by using Map Algebra in ArcGIS, the corrected drug quantity distribution was obtained. This value $q_{i}$, mentioned in (3), is given by

$$
q_{i}=q_{i, r} * R\left(E_{t z}\right)
$$

where $q_{i, r}$ is the TSS distribution mentioned before, which is multiplied by the risk of existence of a retail sale point $R\left(E_{t z}\right)$. The resulting raster layer $q_{i}$ is rescaled to represent the sum of TSS in Bogota.

\section{Market value calculation}

Having this information about quantity and price of each substance, a calculation of the market value represented by the TSS was performed and the total market value was obtained. This was possible by taking into account the aforementioned market value calculation from UNODC.

\section{Results and discussion}

The social cartography exercise allowed the authors to identify 405 retail sale points. From this information, a complex structure of the market in the city was observed, in which several clusters are evidenced, along with scattered points all over the city. By performing a nearest neighbors analysis for this data, with an observed mean distance of $344.0 \mathrm{~m}$, we failed to reject the hypothesis of clustered retail sale points. It is important to remark that, by observing the data from 2010 to 2015 , it was found that this clustered behavior remains even after 5 years.

The prices for all known retail sale points were obtained by mapping such prices with the corresponding police jurisdiction. Performing interpolation on this data, the approximate distribution of prices for each substance in Bogota was obtained. The results of this process are presented in Fig. 1.

In the case of the TSS, in order to show the effect of filtering non-TSS data, a comparison of kernel density estimations for total seizures and TSS seizures is presented in Fig. 2, in which the differences are easily highlighted. It is evident that, for the case of cocaine, seizures reported at specific locations such as the El Dorado International Airport will drag higher densities towards that specific area. Also, by using TSS, several hot spots are found in the city, which confirms the hypothesis of clustered market activity. In Table 1, the percentages of TSSs from total seizures is presented. These percentages stem from the fact that most intelligence operations (that do not correspond to typical surveillance) are focused in high value targets such as cocaine. In contrast, basuco is a common, low-purity, cheap drug, not a usual target for tactical units. For the second correction of seizure data, when evaluating both types of spatial influence in the model, RTMDx carries out an automatic selection of the optimal operationalization for each risk 


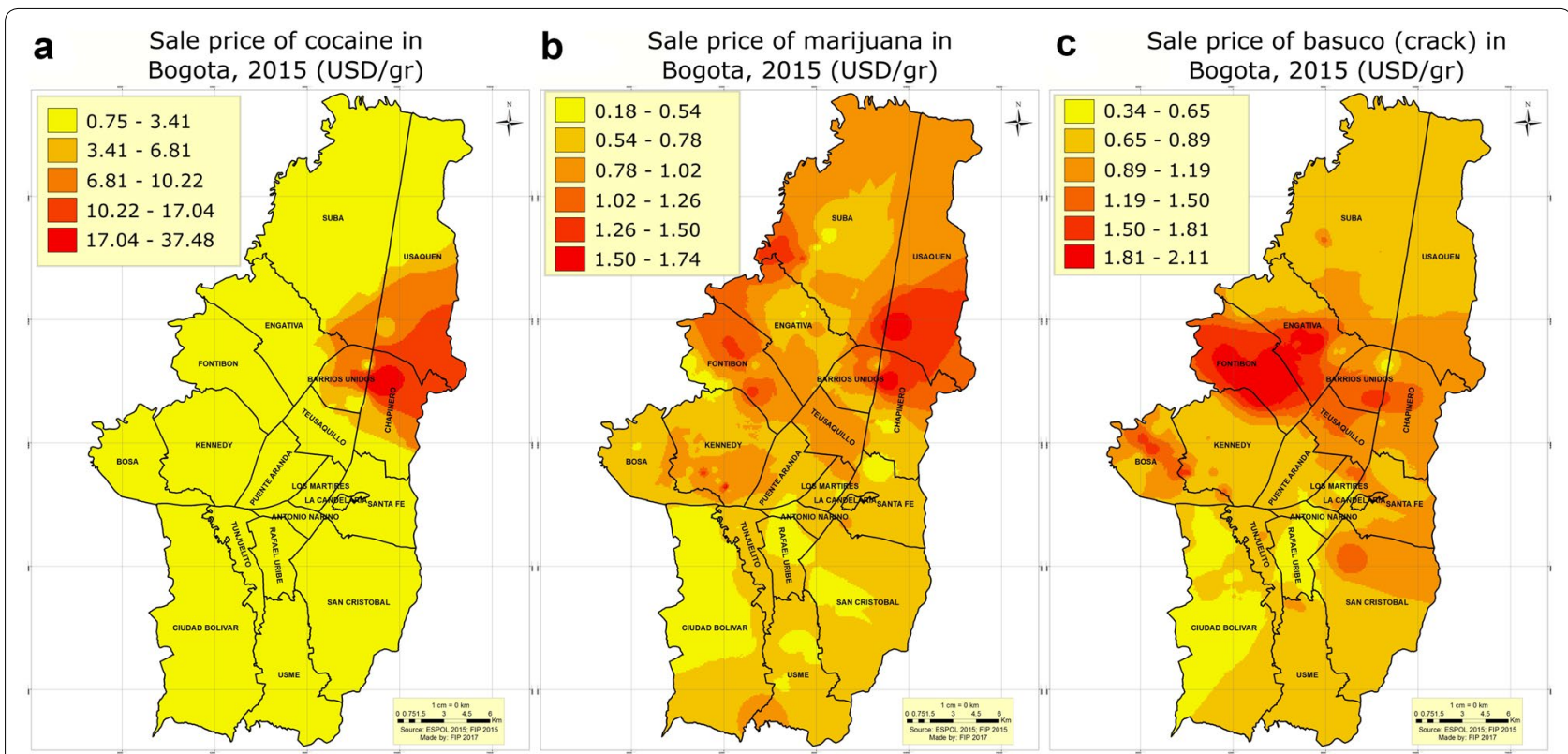

Fig. 1 Prices interpolation for each substance. a Cocaine, b Marijuana and c Basuco

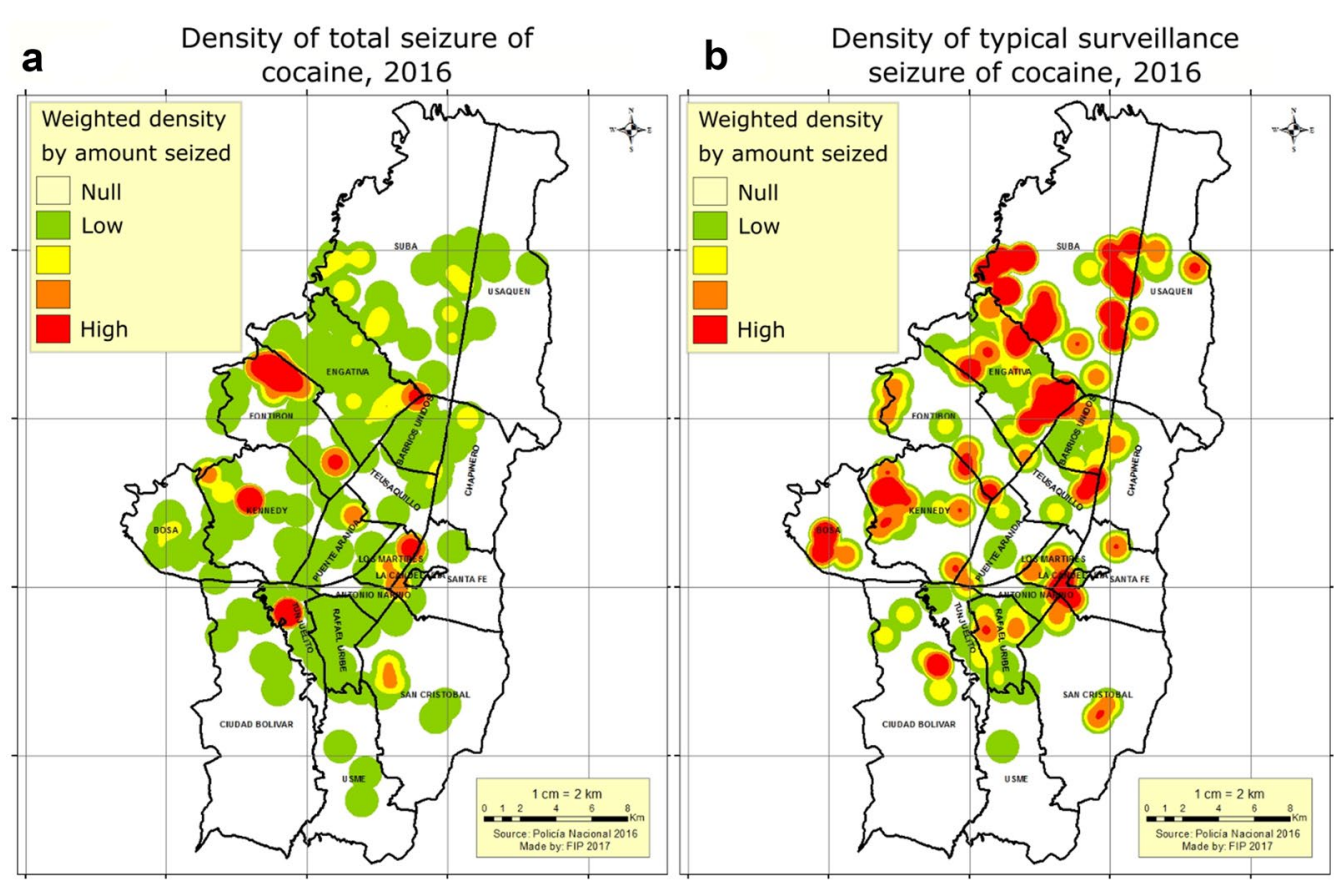

Fig. 2 Effect of filtering for TSS. a Total seizures and $\mathbf{b}$ TSS only

Table 1 Percentage of total seizures represented by TSS

\begin{tabular}{llll}
\hline Substance & Total $\mathbf{( k g )}$ & TSS $(\mathbf{k g})$ & Percentage \\
\hline Marijuana & 2166.9 & 1348 & 62 \\
Basuco & 366 & 300.1 & 82 \\
Cocaine & 276.7 & 21.4 & 8 \\
\hline
\end{tabular}

factor. For this case, the utility determined that the best risk terrain model was a Negative Binomial type II with four risk factors and a BIC score of 2, 962.7. The model also includes an intercept term that represents the background rate of events. The information obtained for the best model, along with spatial influence, coefficients and 
statistical significance is presented in Table 2. Here, the most significant risk factors are shown, being motorcycle theft the first with a spatial influence of proximity within $300 \mathrm{~m}$. This can be explained by the fact that most crimes committed by criminal groups in Colombia are tied to motorcycles: contract killing, "bank jugging", robbery and smuggling; we may say that the strength of this coefficient is given by the presence of gangs that run the business, which is a key factor for drug dealing. This close relationship supports the latest findings of police researchers in Colombia, which identified links between narcotraffic and motorcycle theft (Muñoz 2017). Also, due to the high demand for drugs in nightlife districts, clusters of bars tend to be spatially correlated to drug dealing locations. In these zones, as mentioned by Barnum et al. (2016), drug sales may cause territorial disputes among criminal groups trying to take control of high demand areas, which usually lead to physical violence, quarrels and homicides, these being the second and third risk factors with similar coefficients. In fact, previous evidence shows that at least $55 \%$ of homicides in Bogota occur in seizures locations due to gang disputes (Gómez 2016).The following equation, obtained from RTMDx, represents the risk of existence of a sale point for each grid, which is given by the results shown in Table 2.

$$
R\left(E_{t z}\right)=\frac{\mathrm{e}^{-8.6602+2.8857 t_{m}}+1.0058 h+0.8762 p+0.5723 b}{\mathrm{e}^{-8.6602}},
$$

where $t_{m}$ stands for motorcycle theft, $h$ for homicides, $p$ for personal injuries and $b$ for bar presence. Using (4), the raster layer is calculated through Map Algebra in ArcGIS, and is shown in Fig. 3. After normalizing using a 0 to 1 range, (3) can be applied to obtain the traded quantity from the TSS data.

The accuracy of the model was calculated using the raster layer of Fig. 3 to extract five zones of risk for evaluating model predictions. The way in which this was performed consisted in calculating the percentage of retail sale points located in each of the five risk zones, as displayed in Table 3 for both datasets. Here, the fraction of the total city area represented by each zone is displayed

Table 2 Results of the risk terrain model for existence of a retail sale point delivered by the RTMDx utility

\begin{tabular}{lllll}
\hline Name & $\begin{array}{l}\text { Type of } \\
\text { influence }\end{array}$ & $\begin{array}{l}\text { Influence } \\
(\mathbf{m})\end{array}$ & Coefficient & P value \\
\hline Motorcycle theft & Proximity & 300 & 2.886 & $3.2 \mathrm{e}-21$ \\
Homicide & Density & 400 & 1.006 & $5.8 \mathrm{e}-08$ \\
Personal injuries & Density & 300 & 0.876 & $5.5 \mathrm{e}-11$ \\
Bar & Proximity & 300 & 0.572 & $2.7 \mathrm{e}-05$ \\
Intercept & - & - & -8660 & $3.7 \mathrm{e}-212$ \\
\hline
\end{tabular}

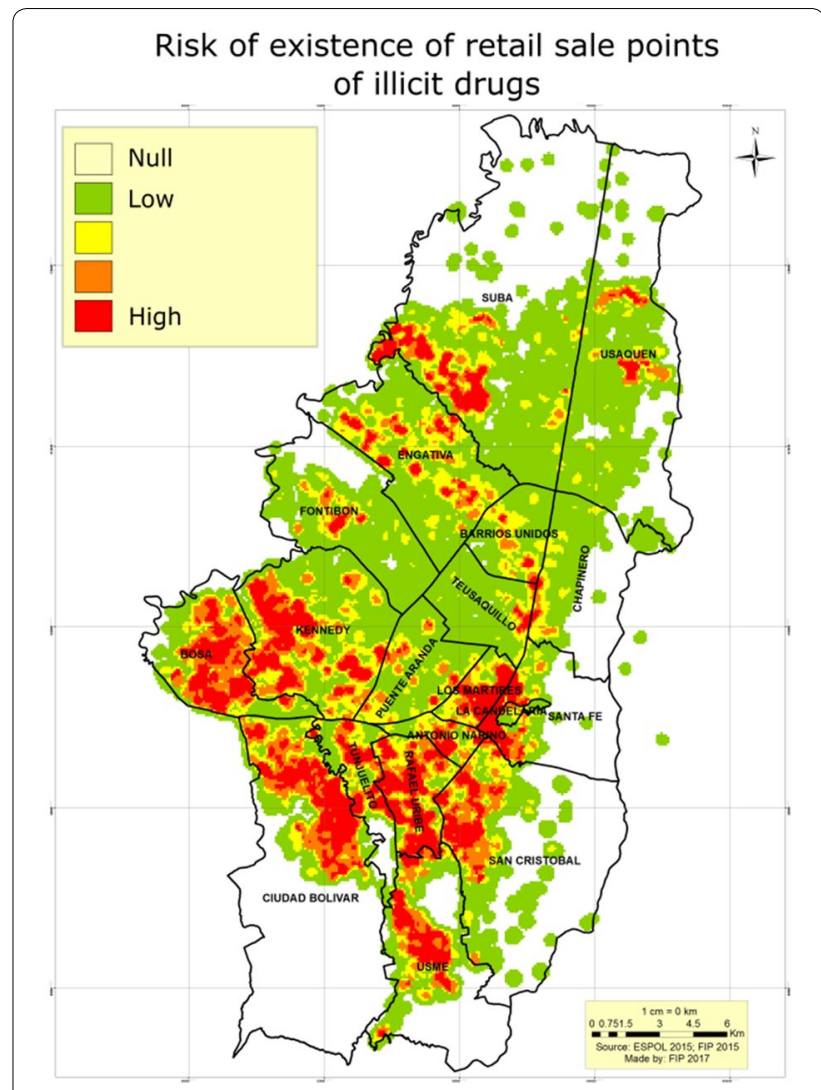

Fig. 3 Risk of existence of sale points in Bogota

\section{Table 3 Model prediction results}

\begin{tabular}{lccc}
\hline Zones & Area (\%) & Training set (\%) & Test set (\%) \\
\hline 1 & 62 & 0 & 0 \\
2 & 22 & 10 & 13 \\
3 & 6 & 27 & 22 \\
4 & 5 & 24 & 30 \\
5 & 5 & 39 & 34 \\
Total & 100 & 100 & 100 \\
\hline
\end{tabular}

Zones 4 and 5 are high risk zones and represent a small area (in italics)

as well. From this information, for the case of training and test sets, an approximate accuracy for high risk zones (zones 4 and 5) of 63 and 64\%, respectively, was obtained. This result is important since the area represented by these zones is about $10 \%$ of the total area of the city.

Having the information of TSSs for all substances, $q_{i, r}$, and the risk of existence of sale points, $R\left(E_{t z}\right)$, (3) is used to obtain the traded quantities of illegal substances represented by the TSS, $q_{i}$. The outcome of correcting for $q_{i, r}$ can be seen in Fig. 4, in which high concentration zones vary significantly from those obtained from the TSS data shown in Fig. 2 for coke 


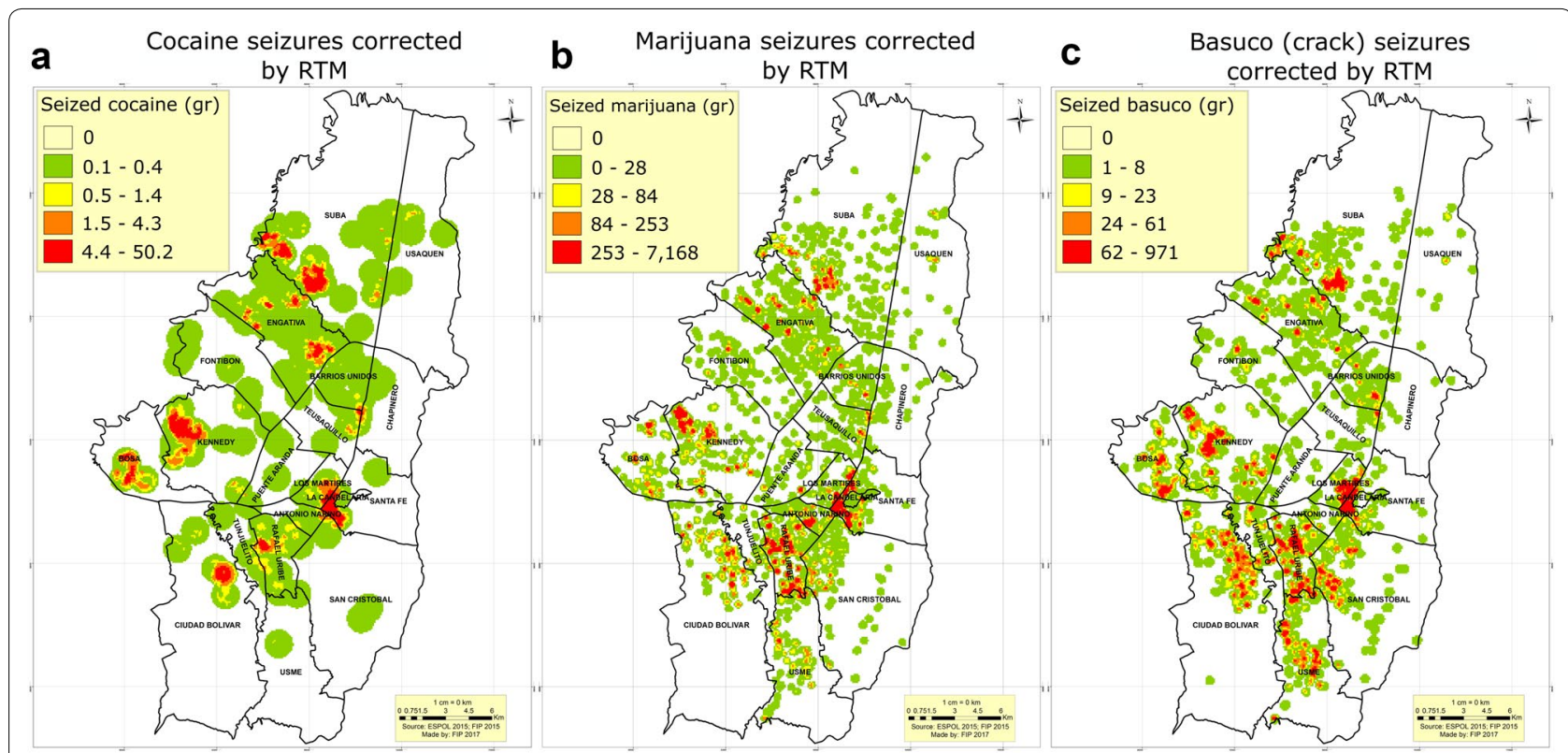

Fig. 4 Seizures corrected. Seizure data corrected by risk of existence of retail sale points. a Cocaine, b Marijuana and c Basuco

seizures. The authors propose the structure from Fig. 4 as a more accurate approximation of the market distribution in Bogota.

After gathering all the information above, it was possible to estimate the market size and its distribution. Taking (1), $p_{i}$ and $q_{i}$, a spatial estimation of the market represented by the TSS is calculated and spatialized, as shown in Fig. 5. Regarding the calculation of the total market value, according to (UNODC 2005), seizures of drugs are assumed to account for the $10 \%$ of the total drug market. From the information in Table 1, the real share of TSS is obtained, namely: 1, 6 and $8 \%$ for cocaine, marijuana and basuco, respectively. Taking this into account, Table 4 presents calculations for total market value of illicit drugs in Bogota in US dollars (USD).$^{5}$

Applying such modeling techniques to illegal activities or crime, where information is poor or even nonexistent (e.g. the drugs market) provides actual evidence to authorities and policy-makers in order to better allocate resources or design intervention strategies. Furthermore, by building improved models and understanding the inherent structures of such markets and the conditions around them, these strategies could be evaluated using fewer resources. This may change the way impact evaluations are performed, requiring less field work in conventional data collection techniques, as mentioned before. Finally, these models allow the researcher to

\footnotetext{
${ }^{5}$ At the time of writing, 1 USD $=2,966 \mathrm{COP}$
}

increase data granularity and perform analysis at different units of analysis, e.g. blocks, neighborhoods and localities, which is not possible with current monitoring methods.

\section{Conclusions}

The present methodology for predicting the risk of drug markets aims to overcome the problems with other approaches by incorporating the spatial component of seizure data and drug prices to obtain the latent market structure. As opposed to most studies, we propose modeling techniques to analyze the supply side of the market and its distribution. This study is relevant since it provides government entities with a more comprehensive alternative for studying drug markets, different than global statistics which generalize prices and ignore spatial behavior of markets. Methodologies such as the one presented in this work, could provide more information to support decision-making processes, e.g. investment, focused interventions and joint analysis with other crimes. It has been shown that, in order to understand the structure of illicit drugs market, the spatial component should be taken into account. Also, the information obtained from RTM models applied in this research provides valuable information for secondary studies, e.g. assessments of drug hot spots and environmental features at risk such as schools and impact evaluations of interventions in the market. As a by-product, this study also helped evaluate the quality and availability of seizure data and crime data from the police department and provided feedback to such institutions. As to future work; 


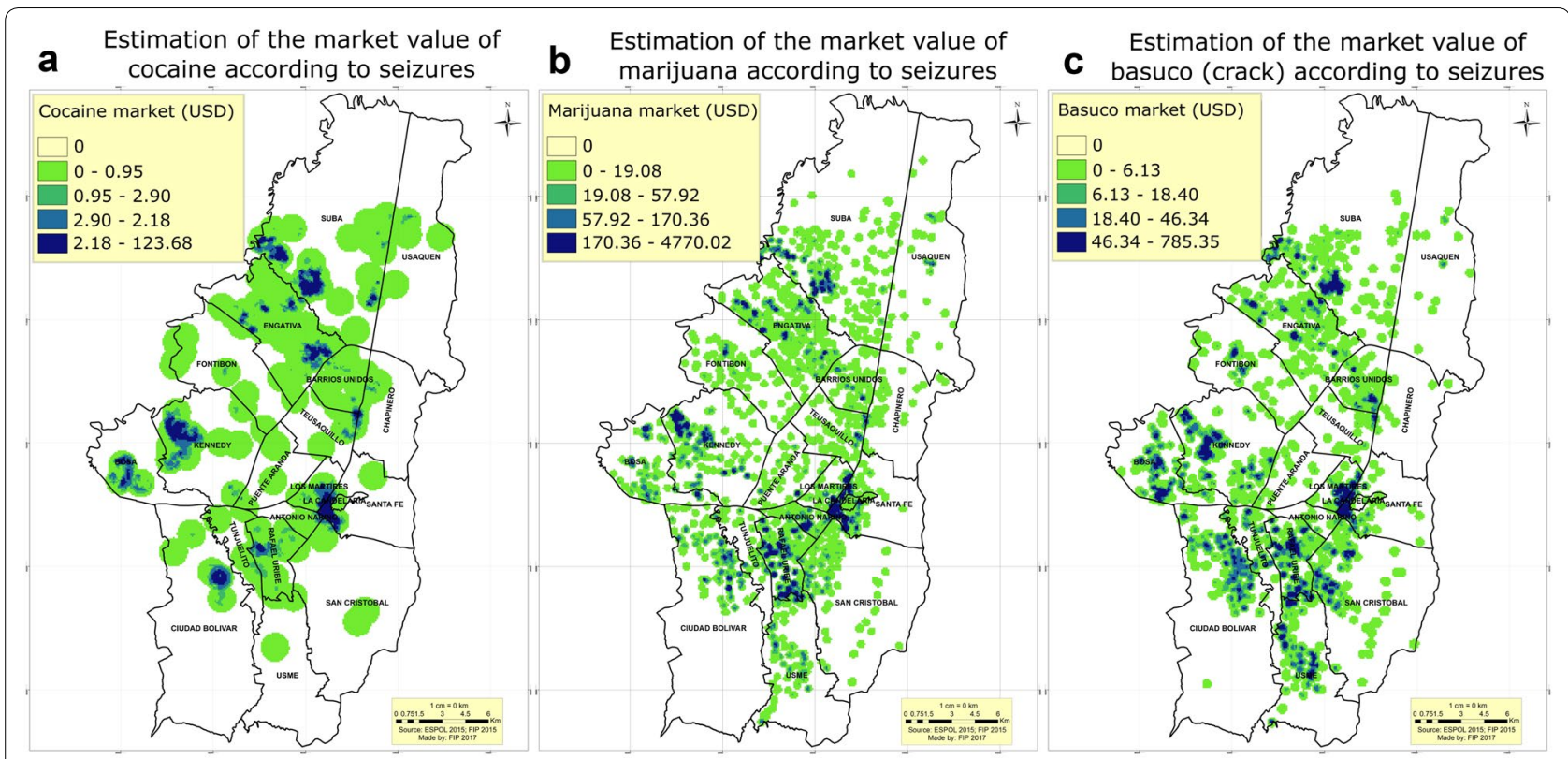

Fig. 5 Distribution of drug markets. Estimated market values represented by seizures. a Cocaine, b Marijuana and c Basuco

Table 4 Calculation of total market value

\begin{tabular}{llll}
\hline Drug & $\begin{array}{l}\text { Market value } \\
\text { from TSS (USD) }\end{array}$ & $\begin{array}{l}\text { Percentage } \\
\text { of total market }\end{array}$ & $\begin{array}{l}\text { Calculated market } \\
\text { value (USD) }\end{array}$ \\
\hline Marijuana & 571,706 & 6 & 9190.061 \\
Basuco & 201,985 & 8 & $2,463,506$ \\
Cocaine & 25,956 & 1 & $3,358,986$ \\
Total & 799,647 & - & $15,012,553$ \\
\hline
\end{tabular}

the authors propose further analysis to assess the percentage of seizures in the real drug market, vital to assess real market values. Similarly, future studies could involve random assessments in the field along with government institutions in charge of interventions.

\section{Abbreviations}

RTM: risk terrain modeling; FIP: Fundación Ideas para la Paz; CAI: Police Command of Immediate Action; GIS: geographic information systems; IDW: inverse distance weighting; TSS: typical surveillance seizures.

\section{Authors' contributions}

The Fundación Ideas para la Paz assisted by the Police Department of Bogota carried outthe field work, which was coordinated by BR. The design of the methodology was lead byBR, who was in charge of spatial analysis and visualization. JAE was the lead writer ofthis paper, carrying out the necessary literature review and performing data cleaning andRTM modeling. All authors read and approved the final manuscript.

\section{Acknowledgements}

To ESPOL-PONAL (Police Department School) for their contribution during the fieldworkwith all Police majors. To the CEO of Fundación Ideas para la Paz, Maria Victoria Llorenteand researchers Rodolfo Escobedo, Maria Paula Lovera, and Camila Patiño, among others,for their technical support and advice.

\section{Competing interests}

The authors declare that they have no competing interests.

\section{Availability of data and materials}

Articles used in the systematic review are noted in the references. For other informationregarding data, please contact the lead author.

\section{Consent for publication}

Not applicable.

Ethics approval and consent to participate

Not applicable.

\section{Funding}

The research reported here was funded by Open Society Foundations Grant OR 2015-24886.

\section{Publisher's Note}

Springer Nature remains neutral with regard to jurisdictional claims in published maps and institutional affiliations.

Received: 17 October 2017 Accepted: 22 December 2017 Published online: 05 February 2018

\section{References}

Alvarado, L. E. (2013). Microtráfico y narcomenudeo: caracterización del problema de las drogas en pequeñas cantidades en colombia. Bogotá: Ministerio de Justicia y del Derecho - Dirección de política contra las drogas y actividades relacionadas.

Barnum, J. D., Campbell, W. L., Trocchio, S., Caplan, J. M., \& Kennedy, L. W. (2016). Examining the environmental characteristics of drug dealing locations. Crime and Delinquency, 63(13), 1731-1756. https://doi. org/10.1177/0011128716649735.

Barreras, F., Diaz, C., Riascos, A., \& Ribero, M. (2016). Una comparación de diferentes modelos para la predicción del crimen en bogotá (a comparison of different crime prediction models for bogotá). Tech. rep., Universidad de 
los Andes Department of Economics Research Paper Series (Documentos CEDE). https://doi.org/10.2139/ssrn.2940343

Bernasco, W., \& Block, R. (2011). Robberies in chicago: A block-level analysis of the influence of crime generators, crime attractors, and offender anchor points. Journal of Research in Crime and Delinquency, 48(1), 33-57.

Caplan, J. M., Kennedy, L. W., \& Miller, J. (2011). Risk terrain modeling: Brokering criminological theory and gis methods for crime forecasting. Justice Quarterly, 28(2), 360-381.

Caplan, J. M., Kennedy, L. W., \& Piza, E. L. (2013). Risk terrain modeling diagnostics utility (1st ed.). Newark: Rutgers Center on Public Security.

Caplan, J. M., Marotta, P., Piza, E. L., \& Kennedy, L. (2014). Risk terrain modeling for strategic and tactical action. Crime Mapping and Analysis News, 1(4) 10-13.

Caplan, J. M., Kennedy, L. W., Barnum, J. D., \& Piza, E. L. (2015). Risk terrain modeling for spatial risk assessment. Cityscape, 17(1), 7 .

Caulkins, J. P., \& Reuter, P. (2010). How drug enforcement affects drug prices. Crime and Justice, 39(1), 213-271.

Chainey, S., Tompson, L., \& Uhlig, S. (2008). The utility of hotspot mapping for predicting spatial patterns of crime. Security Journal, 27(1-2), 4-28.

Daley, D., Bachmann, M., Bachmann, B. A., Pedigo, C., Bui, M. T., \& Coffman, J. (2016). Risk terrain modeling predicts child maltreatment. Child Abuse and Neglect, 62, 29-38.

de Bogotá, A. (2016). Estudio de consumo de sustancias psicoactivas en bogotá. Bogotá: d.c Tech. rep., Alcaldía de Bogotá.

Departamento Nacional de Planeación (2016). narcomenudeo, un lucrativo negocio que mueve $\$ 6$ billones anuales. https://www.dnp.gov.co/Paginas/Narcomenudeo,-un-lucrativo-negocio-que-mueve-6-billones-de\%20 pesos\%20anuales.aspx. Reviewed in July 2017.

Drawve, G., Moak, S. C., \& Berthelot, E. R. (2016). Predictability of gun crimes: A comparison of hot spot and risk terrain modelling techniques. Policing and Society, 26(3), 312-331. https://doi.org/10.1080/10439463.2014.942 851.

Dugato, M. (2013). Assessing the validity of risk terrain modeling in a european city: Preventing robberies in the city of milan. Crime Mapping, 5(1), 63-89.

Garzón, J. C., Wilches, J., \& Bernal, J. L. (2017). Las revelaciones del bronx intervención de zonas de alta complejidad: Desafíos y alternativas. Bogota: Fundación Ideas para la Paz.
Gómez, Y. (2016). Siete claves para intervenir zonas calientes del crimen en bogotá. http://www.eltiempo.com/archivo/documento/CMS-16493739. Reviewed in November 2017

Jacobson, J., \&Webb, B. (1999). Policing drug hot-spots (5th ed.). London: Home Office.

Kennedy, L. W., Caplan, J. M., \& Piza, E. (2011). Risk clusters, hotspots, and spatial intelligence: Risk terrain modeling as an algorithm for police resource allocation strategies. Journal of Quantitative Criminology, 27(3), 339-362.

Kennedy, L. W., Caplan, J. M., Piza, E. L., \& Buccine-Schraeder, H. (2015). Vulnerability and exposure to crime: Applying risk terrain modeling to the study of assault in chicago. Applied Spatial Analysis and Policy, 9(4), 529-548.

Kocher, M., \& Leitner, M. (2015). Forecasting of crime events applying risk terrain modeling. Gl_Forum, 2015, 30-40.

McCord, E. S., \& Ratcliffe, J. H. (2007). A micro-spatial analysis of the demographic and criminogenic environment of drug markets in Philadelphia. Australian and New Zealand Journal of Criminology, 40(1), 43-63.

Muñoz, C. (2017). Bandas de narcotráfico también están detrás del hurto de motocicletas. http://www.elespectador.com/noticias/judicial/bandasde-narcotrafico-tambien-estan-detras-del-hurto-de-motocicletas-articulo-695346. Reviewed in July 2017

Oliveira, E., Silva, B. F. A., \& Prates, M. O. (2015). Street drug markets beyond favelas in belo horizonte, Brazil. Crime Science, 4(1), 36. https://doi. org/10.1186/s40163-015-0048-z.

Ramirez. B., Bulla, P., Rodríguez, D., García, J., Acosta, M., \& Caicedo, R. (2014). Focalizar el trabajo policial sí reduce el crimen. http://www.ideaspaz.org/ publications/posts/1072. Reviewed in November 2017.

Rengert, G., Chakravorty, S., Bole, T., \& Henderson, K. (2000). A geographic analysis of illegal drug markets. Crime Prevention Studies, 11, 219-240.

Robinson, J. B., \& Rengert, G. F. (2006). Illegal drug markets: The geographic perspective and crime propensity. Western Criminology Review, 7(1), 20-32.

UNODC. (2005). Estimating the value of illicit drug markets. United Nations, Chap, 2, 123-143.

\section{Submit your manuscript to a SpringerOpen ${ }^{\circ}$ journal and benefit from:}

- Convenient online submission

- Rigorous peer review

- Open access: articles freely available online

- High visibility within the field

- Retaining the copyright to your article

Submit your next manuscript at $\boldsymbol{\nabla}$ springeropen.com 